\title{
一种可为锂二次电池提供过热保护的正温度敏感 系数电极
}

夏兰, 朱利敏, 张海燕, 艾新平*

武汉大学化学与分子科学学院, 湖北省化学电源材料与技术重点实验室, 武汉 430072

*联系人, E-mail: xpai@whu.edu.cn

2011-11-01 收稿, 2011-12-08 接受

国家重点基础研究发展计划(2009CB220100)、国家高技术研究发展计划(2011AA11A256, 2011AA11A254)和中央高校基本科研业务费专项 资金资助

摘要通过将导电碳黑(carbon black, CB) Super P 均匀地分散到聚甲基丙烯酸甲酯 (poly(methyl methacrylate), PMMA) 的聚合物基质中, 发展出了一种具有正温度敏感系数 (positive temperature coefficient, PTC) 特征的 CB-PMMA 复合材料, 并采用该复合材料为铝 簿基体的表面涂层, 制备出具有三明治结构的 $\mathrm{Al} / \mathrm{PTC} / \mathrm{LiCoO}_{2}$ 阴极。通过循环伏安扫 描、倍率充放电和交流阻抗等方法考察了 PTC 复合电极在常温和高温下的电化学性能。实 验结果表明, PTC- $\mathrm{LiCoO}_{2}$ 电极在常温下具有高的充放电比容量、良好的倍率性能和循环稳 定性, PTC 涂层对 $\mathrm{LiCoO}_{2}$ 电极的正常充放电没有产生明显的不利影响. 但在 $80 \sim 120^{\circ} \mathrm{C}$ 的 高温下, PTC 涂层因电阻急剧增大约 2 个数量级, 限制了电极活性层与集流体之间的电流 传输, 导致电极容量的急剧下降, 表现出良好的自激发热阻断效果, 从而可以防止电池因 热失控而引发的安全性问题.
关键词

锂离子电池

正温度系数

安全性

聚甲基丙烯酸甲酯

热失控
来自环境污染和石油资源贵乏的双重压力极大 地推动了电动汽车的发展. 锂离子电池因比能量 高、循环性能好等显著优势, 成为车用动力电池研发 的重点 ${ }^{[1 \sim]}$. 然而, 不断发生的安全性事故严重地阻 碍了大容量和高功率锂离子电池的商业化应用 ${ }^{[5 \sim 7]}$. 锂离子电池采用高氧化性的正极、强还原性的负极以 及易燃性的有机电解液, 除了正常的充电-放电反应 外, 还存在众多潜在的放热副反应, 如电极材料表面 SEI 膜的热分解, 以及由此而导致的电解液在裸露电 极表面的大量分解放热 ${ }^{[8]}$, 充电态正极的热分解放热, 以及进一步引发的电解液分解等 ${ }^{[9]}$. 在正常使用条件 下，上述副反应不会发生. 但当内外部短路、过充电 等滥用条件导致电池的温度过高时, 上述反应有可 能被引发, 并在短时间内放出大量的热及可燃性有 机小分子气体 ${ }^{[10 ~ 12]}$. 热量在电池体内的大量积累导
致电池内部温度的急剧升高, 并进一步加速副反应 的发生, 从而使电池进人危险的热失控状态, 并可能 引发电池燃烧、爆炸等安全性事故 ${ }^{[13]}$.

目前, 提高锂离子电池安全性的主要措施包括: (1) 采用阻燃或不燃性电解液. 虽然阻燃型添加剂的 加人, 有效降低了电解液的可燃性, 但是对电池的循 环和倍率性能产生了非常严重的不利影响 ${ }^{[14,15]}$. (2) 采用无机氧化物陶瓷修饰的耐热涂层隔膜(或电极). 虽然耐热涂层可以有效防止因温度升高致使隔膜收 缩而引起的内部短路, 但是对由于过热引起的其他 副反应和外部短路、过充等引起的热失控却无能为

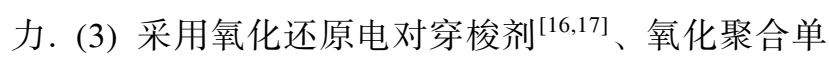
体添加剂 ${ }^{[18]}$, 以及电压敏感隔膜 ${ }^{[19]}$ 等防止电池过充. 但这些技术措施仅对过充响应，并不能成为电池的 热保护技术. 商品化锂离子电池的隔膜通常是聚烯 
烃类的聚合物, 如聚丙烯/聚乙烯/聚丙烯 $(\mathrm{PP} / \mathrm{PE} / \mathrm{PP})$ 三层结构, 此种隔膜具有热封闭功能. 当温度上升至 $\mathrm{PE}$ 的熔点时, PE 层的微孔由于熔化发生坉塌, 使隔 膜失去离子导电性而成为绝缘层, 防止离子的传输, 切断电流, 从而防止热失控的发生 ${ }^{[20]}$. 然而, 如果不 能及时散热, 温度的进一步上升会导致隔膜的熔化, 引起内部短路, 导致危险发生. 因此, 这种功能的隔 膜并不能真正地确保电池的安全.

基于复合型导电聚合物材料较强的 PTC 效 应 $^{[21 \sim 23]}$, 在几年前的工作中, 我们报道了一种采用 环氧树脂-碳黑复合物为 PTC 材料, 通过在集流体和 活性涂层之间置人 PTC 薄层制备出 PTC 电极 ${ }^{[24]}$. 研 究表明, 在 $100 \sim 130^{\circ} \mathrm{C}$ 的温度范围内, 电极电阻急剧 上升, 电极反应被有效抑制, PTC 电极表现出对电池 有效的热保护功能. 然而, 由于 PTC 层的制备涉及 到环氧树脂长时间的固化，在工业化制备和实际应 用方面存在不小的困难.

为简化 PTC 电极的制备过程, 开发适合于实际 体系应用的温度敏感电极, 本工作中, 我们通过将导 电碳黑(CB)-Super P 均匀地分散到聚甲基丙烯酸甲酯 (PMMA)的聚合物基质中, 发展出了一种具有正温度 敏感系数(PTC)特征的 CB-PMMA 复合材料, 并采用 该复合材料为铝箔基体的表面涂层, 制备出具有三 明治结构的 $\mathrm{Al} / \mathrm{PTC} / \mathrm{LiCoO}_{2}$ 阴极, 并考察了 PTC 复合 电极在常温和高温下的电化学性能.

\section{1 材料和方法}

(i) PTC 电极的制备. 实验所用 PTC 材料为超 导碳黑 (Super P)与聚甲基丙烯酸甲酯(PMMA)按质量 比 1:9 的混合物. PTC 电极的制备过程为: 按一定质 量比将 Super-P 加人到 PMMA $\left(M_{\mathrm{w}}=996000 \mathrm{~g} / \mathrm{mol}\right)$ 的 氯仿溶液中, 行星球磨 $6 \mathrm{~h}$ 得到均匀分散的 PTC 浆料. 将此 PTC 浆料通过拉浆机涂布到集流体 $\mathrm{Al}$ 䇴上, $70^{\circ} \mathrm{C}$ 烘箱中干燥 $24 \mathrm{~h}$, 使氯仿完全挥发. 然后, 将 PVDF、乙炔黑和正极活性物质 $\mathrm{LiCoO}_{2}$ 以 7:3:90 的 质量比混合调浆后, 涂于 PTC 层上, 构成 PTC 电极, 调浆所用溶剂为 $N$-甲基吡咯烷酮.

(ii) 性能表征. PTC 材料在不同温度下的电导 率由万能表测电阻后换算获得. 具体过程为: 将涂覆 制备的 PTC 膜夹在两铅簿之间, 用模具夹住后置于 鼓风干燥箱中. 温度变化区间为 $20 \sim 130^{\circ} \mathrm{C}$. 在每一 测试温度下, 保温 $1 \mathrm{~h}$ 后再进行电阻测量. 电化学性
能测试采用所制备的温度敏感电极装配 2016 扣式电 池, 对电极为金属锂片. 电池的装配在充满氩气的手 套箱中进行. 恒电流充放电实验由计算机程序控制, 所用仪器为武汉蓝电 CT2001A 电池测试系统. 充放 电电压范围为 4.3 3.0 V. 使用 CHI660A 型(上海辰华 仪器公司)电化学工作站测量电池的循环伏安和交流 阻抗行为.

\section{2 结果与讨论}

复合型导电聚合物 PTC 材料是将导电微粒分散 填充在聚合物骨架之中构成的一种新型功能高分子 材料. 通常, 这类材料由于聚合物骨架与导电颗粒的 热膨胀系数不同, 在温度升高时, 原有的导电网络被 破坏, 引起材料的电阻急剧升高, 从而显示 PTC 效 应 ${ }^{[25,26]}$. 本文中, 我们通过将导电碳黑 (CB)-Super P 均匀地分散到聚甲基丙烯酸甲酯(PMMA)的聚合物 基质中, 发展出了一种具有正温度敏感系数(PTC)特 征的 CB-PMMA 复合材料. 由于室温下 PMMA 溶于 氯仿而不溶于 $N$-甲基吡咯烷酮, 所以可以制备出均 匀分散的 PTC 浆料, 方法简单可行.

图 1 给出了 CB-PMMA 复合材料电导率随温度 的变化曲线. 从图中可以看出, 在 $40 \sim 80^{\circ} \mathrm{C}$ 的区间内, CB-PMMA复合材料电导率的减小缓慢; 当温度超过 $80^{\circ} \mathrm{C}$ 时, 电导率迅速减小约 2 个数量级, 显示出良好 的 PTC 效应. 一般认为, 锂离子电池的工作温度不 能高于 $100^{\circ} \mathrm{C}$. 因此, 我们选择的 CB-PMMA 复合材 料可以为锂离子电池提供热阻断保护, 提高电池的 安全性.

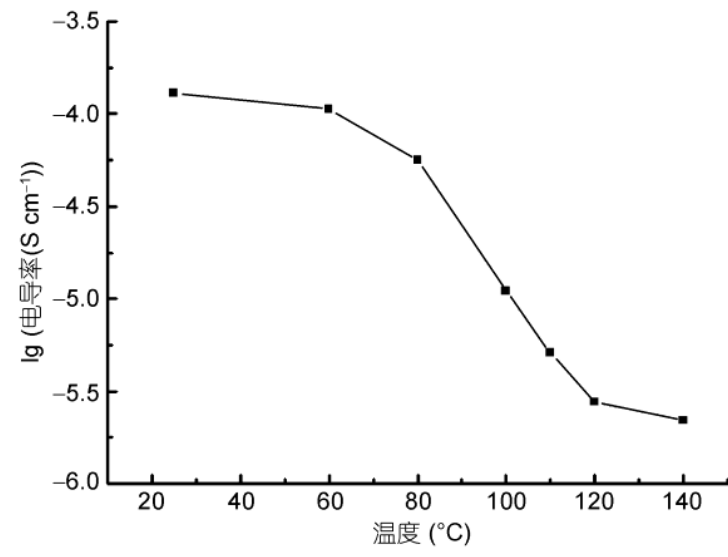

图 1 CB-PMMA 复合材料的电导率随温度变化曲线 CB, $10 \mathrm{wt} \%$; PMMA, $90 \mathrm{wt} \%$ 
为了弄清楚在正常条件下 PTC 层对电池是否有 影响, 我们考察了 PTC 电极在正常条件下的循环伏 安曲线和倍率性能曲线 (见图 2). 从图 2(a)可以看出, PTC- $\mathrm{LiCoO}_{2}$ 电极出现一对可逆的氧化还原峰. 其中, 氧化峰出现在 $4.10 \mathrm{~V}$, 相对应的还原峰出现在 $3.80 \mathrm{~V}$, 和空白 $\mathrm{LiCoO}_{2}$ 电极相一致, 表明 PTC 层没有对电池 产生负面影响. 同时, 图 2(b)给出了 $\mathrm{PTC}-\mathrm{LiCoO}_{2}$ 电 极在常温下的循环倍率性能. 从图 2(b)中可以看出, $\mathrm{PTC}-\mathrm{LiCoO}_{2}$ 电极在 $0.25 \mathrm{C}$ 的放电容量为 $140 \mathrm{mAh} / \mathrm{g}$; 随着倍率从 0.5 增加到 $1 \mathrm{C}, \mathrm{PTC}-\mathrm{LiCoO}_{2}$ 电极的放电 容量仍分别为 135 和 $123 \mathrm{mAh} / \mathrm{g}$; 甚至在 $2 \mathrm{C}$ 的倍率 下容量保持在 $100 \mathrm{mAh} / \mathrm{g}$, 显示了理想的倍率性能. 这些数据表明, 在常温下, PTC 层没有明显的欧姆极 化. 并且, 循环 50 周后, 以 $0.25 \mathrm{C}$ 的倍率充放电, 容 量保持率几乎为 $100 \%$, 显示出良好的循环稳定性.

为了证明 $\mathrm{PTC}-\mathrm{LiCoO}_{2}$ 电极的实际热阻断效果,
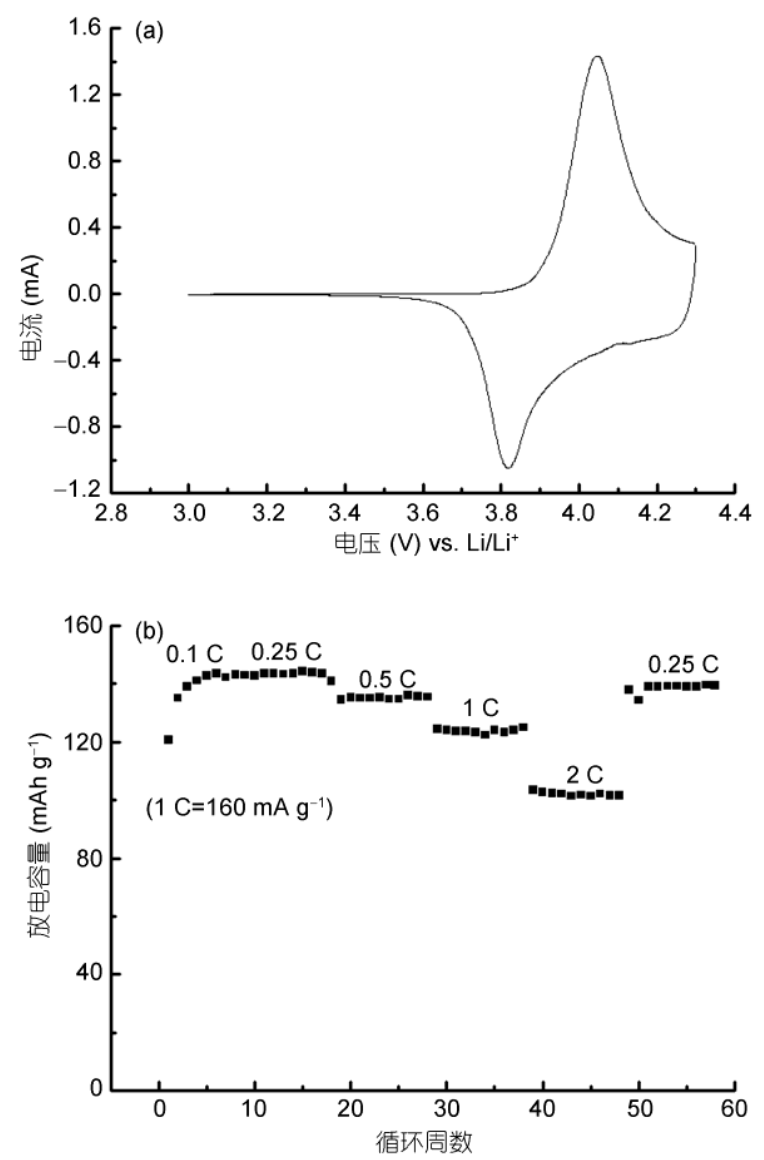

图 2 常温下 PTC- $\mathrm{LiCoO}_{2}$ 电极的电化学性能

(a) 循环伏安曲线, 扫速为 $0.1 \mathrm{mV} / \mathrm{s}$; (b) 不同倍率下的循环稳定性能 曲线, 电流密度分别为 $20(0.1 \mathrm{C}), 40(0.25 \mathrm{C}), 80$ (0.5 C), 160 (1 C) 和 $320(2 \mathrm{C}) \mathrm{mA} / \mathrm{g}$
图 3 给出了 $\mathrm{PTC}-\mathrm{LiCoO}_{2}$ 电极为正极的模拟电池在不 同的温度下的充放电曲线. 图 3 中可以看出, 在 $30^{\circ} \mathrm{C}$ 时 PTC- $\mathrm{LiCoO}_{2}$ 具有与空白电池基本一致的充放电平 台和可逆充放电容量, 放电容量为 $130 \mathrm{mAh} / \mathrm{g}$, 表明 PTC 涂层并没有影响电极材料的正常充放电行为. 随着温度的上升, 电池充电平台不断升高, 放电平台 不断降低, 可逆充放电容量减小. 表明温度升高导致 PTC 涂层的电阻增大, 电极出现了较为明显的欧姆 极化, 从而影响到电池的正常充放电. 当温度升高至 $90^{\circ} \mathrm{C}$ 时, 充电电压升高 ca. $100 \mathrm{mV}$, 放电电压降低 ca. $200 \mathrm{mV}$, 电池放电容量下降为 $80 \mathrm{mAh} / \mathrm{g}$; 继续上升 至 $110^{\circ} \mathrm{C}$ 时, 电池首周充电容量下降到 $55.8 \mathrm{mAh} / \mathrm{g}$, 而放电容量仅为 $8.4 \mathrm{mAh} / \mathrm{g}$, 随后, 电池失去了正常 的充放电性能。上述结果表明，所制备的 PTC- $\mathrm{LiCoO}_{2}$ 电极随着温度的升高, PTC 涂层因电阻 急剧增大约 2 个数量级, 限制了电极活性层与集流体 之间的电流传输, 导致电极容量的急剧下降, 表现出 良好的自激发热阻断效果，从而可以防止电池因热 失控而引发的安全性问题.

图 4 给出了 $\mathrm{PTC}-\mathrm{LiCoO}_{2}$ 电极制备成的电池在不 同温度下的电化学阻抗图谱(EIS). 从图中可以看出, 在 $30^{\circ} \mathrm{C}$ 时 $\mathrm{PTC}-\mathrm{LiCoO}_{2}$ 电池的阻抗图谱(EIS)包括高 频区域与电荷传递相关的半圆和低频区域与锂离子 在活性材料中固态扩散相关的斜线两部分. 当温度 升高至 $90^{\circ} \mathrm{C}$ 时, 高频区半圆的直径是 $30^{\circ} \mathrm{C}$ 时的 15 倍 左右; 随着温度升高到 $110^{\circ} \mathrm{C}$, 阻抗谱近似为一条直 线. 由此表明, 随着温度的升高, 电池出现极大的欧 姆极化, 随即可切断电流, 提高了电池的热稳定性.

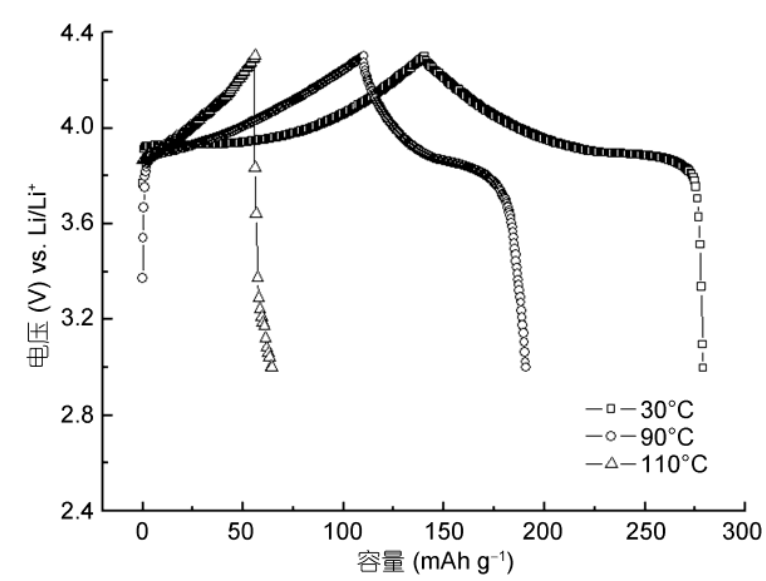

图 3 PTC- $\mathrm{LiCoO}_{2}$ 电极在不同温度下的充放电曲线 电流密度为 $40 \mathrm{~mA} / \mathrm{g}$ 


\section{3 结论}

通过将导电碳黑(CB)Super P 均匀地分散到聚 甲基丙烯酸甲酯(PMMA)的聚合物基质中, 发展出 了一种具有正温度敏感系数 (P T C ) 特征的 CB-PMMA 复合材料, 并采用该复合材料为铝箔基 体的表面涂层，制备出具有三明治结构的 $\mathrm{Al} / \mathrm{PTC} / \mathrm{LiCoO}_{2}$ 阴极. 实验结果表明, PTC- $\mathrm{LiCoO}_{2}$ 电极在常温下具有高的充放电比容量、良好的倍率 性能和循环稳定性, 表明 PTC 涂层对 $\mathrm{LiCoO}_{2}$ 电极的 正常充放电没有产生明显的不利影响。但在 $80 \sim 120^{\circ} \mathrm{C}$ 的高温下, PTC 涂层因电阻急剧增大约 2 个数量级，限制了电极活性层与集流体之间的电流 传输, 导致电极容量的急剧下降, 表现出良好的自 激发热阻断效果，从而可以防止电池因热失控而引

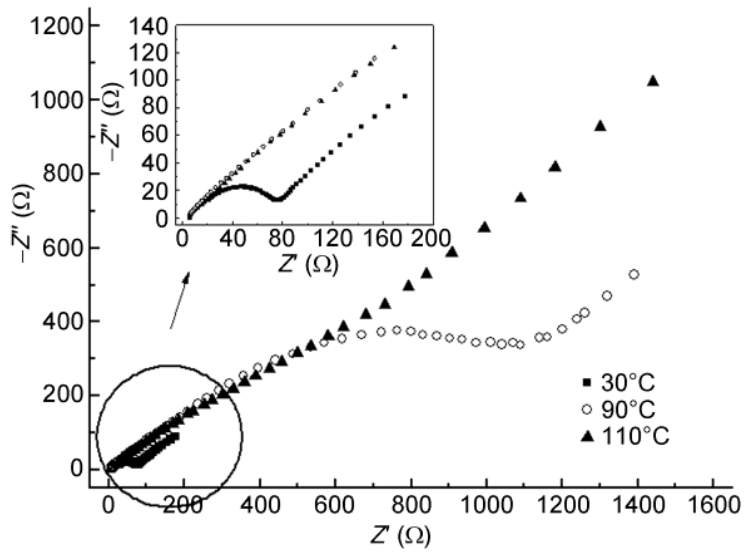

图 4 PTC- $\mathrm{LiCoO}_{2}$ 电极在不同温度下的交流阻抗图谱

发的安全性问题. 因此, 本研究为构建可行、安全的 锂离子电池动力与储能电源体系提供了思路.

\section{参考文献}

1 Armand M, Tarascon J M. Building better batteries. Nature, 2008, 451: 652-657

2 Etacheri V, Marom R, Elazari R, et al. Challenges in the development of advanced Li-ion batteries: A review. Energy Environ Sci, 2011, 4: 3243-3262

3 熊小芹, 蒋妍, 夏圣安, 等. 高度有序 $\mathrm{LiNi}_{2 / 3} \mathrm{Mn}_{1 / 3} \mathrm{O}_{2}$ 正极材料的制备与改性. 科学通报, 2010, 55: 2520-2525

4 Gao X P, Yang H X. Multi-electron reaction materials for high energy density batteries. Energy Environ Sci, 2010, 3: 174-189

5 Goodenough J B, Kim Y. Challenges for rechargeable Li batteries. Chem Mater, 2009, 22: 587-603

6 Tarascon J M, Armand M. Issues and challenges facing rechargeable lithium batteries. Nature, 2001, 414: 359-367

7 Scrosati B, Garche J. Lithium batteries: Status, prospects and future. J Power Sources, 2010, 195: 2419-2430

8 Bandhauer T M, Garimella S, Fuller T F. A critical review of thermal issues in lithium-ion batteries. J Electrochem Soc, 2011, 158: R1-R25

9 Pérès J P, Perton F, Audry C, et al. A new method to study Li-ion cell safety: Laser beam initiated reactions on both charged negative and positive electrodes. J Power Sources, 2001, 97-98: 702-710

10 Zhang Z, Fouchard D, Rea J R. Differential scanning calorimetry material studies: Implications for the safety of lithium-ion cells. J Power Sources, 1998, 70: 16-20

11 Yamaki J I, Baba Y, Katayama N, et al. Thermal stability of electrolytes with $\mathrm{Li}_{x} \mathrm{CoO}_{2}$ cathode or lithiated carbon anode. J Power Sources, 2003, 119-121: 789-793

12 Baba Y, Okada S, Yamaki J I. Thermal stability of $\mathrm{Li}_{x} \mathrm{CoO}_{2}$ cathode for lithium ion battery. Solid State Ionics, 2002, 148: 311-316

13 Tobishima S I, Takei K, Sakurai Y, et al. Lithium ion cell safety. J Power Sources, 2000, 90: 188-195

14 Leising R A, Palazzo M J, Takeuchi E S, et al. A study of the overcharge reaction of lithium-ion batteries. J Power Sources, 2001, 97-98: 681-683

15 Balakrishnan P G, Ramesh R, Prem K T. Safety mechanisms in lithium-ion batteries. J Power Sources, 2006, 155: 401-414

16 Zhang Z, Zhang L, Schlueter J A, et al. Understanding the redox shuttle stability of 3,5-di-tert-butyl-1,2-dimethoxybenzene for overcharge protection of lithium-ion batteries. J Power Sources, 2010, 195: 4957-4962

17 Chen Z, Qin Y, Amine K. Redox shuttles for safer lithium-ion batteries. Electrochim Acta, 2009, 54: 5605-5613

18 Feng J K, Cao Y L, Ai X P, et al. Tri-(4-methoxythphenyl) phosphate: A new electrolyte additive with both fire-retardancy and overcharge protection for Li-ion batteries. Electrochim Acta, 2008, 53: 8265-8268

19 Li S L, Xia L, Zhang H Y, et al. A poly(3-decyl thiophene)-modified separator with self-actuating overcharge protection mechanism for $\mathrm{LiFePO}_{4}$-based lithium ion battery. J Power Sources, 2011, 196: 7021-7024 
20 Jeong $\mathrm{H} \mathrm{S}$, Lee S Y. Closely packed $\mathrm{SiO}_{2}$ nanoparticles/poly(vinylidene fluoride-hexafluoropropylene) layers-coated polyethylene separators for lithium-ion batteries. J Power Sources, 2011, 196: 6716-6722

21 Shen L, Lou Z D, Qian Y J. Effects of thermal volume expansion on positive temperature coef ficient effect for carbon black filled polymer composites. J Polym Sci Part A: Polym Phys, 2007, 45: 3078-3083

22 Zheng W, Wong S C. Electrical conductivity and dielectric properties of PMMA/expanded graphite composites. Compos Sci Technol, 2003, 63: 225-235

23 Dang Z M, Li W K, Xu H P. Origin of remarkable positive temperature coefficient effect in the modified carbon black and carbon fiber cofillled polymer composites. J Appl Phys, 2009, 106: 024913

24 Feng X M, Ai X P, Yang H X. A positive-temperature-coefficient electrode with thermal cut-off mechanism for use in rechargeable lithium batteries. Electrochem Commum, 2004, 6: 1021-1024

25 Li Q, Siddaramaiah, Kim N H, et al. Positive temperature coefficient characteristic and structure of graphite nanofibers reinforced high density polyethylene/carbon black nanocomposites. Compos Part B: Eng, 2009, 40: 218-224

26 Jiang S L, Yu Y, Xie J J, et al. Positive temperature coefficient properties of multiwall carbon nanotubes/poly(vinylidene fluoride) nanocomposites. J Appl Polym Sci, 2010, 116: 838-842 